\title{
Blended Startups: Combining IT with Social, Mobile, Instant Communities
}

\author{
Bennett Cherry \\ California State University San Marcos \\ bcherry@csusm.edu
}

\begin{abstract}
In this paper, three IT-based startups are presented that have each "hitched their wagon to a star" " and have built their fledgling enterprise by blending the social, mobile, and instant elements of IT into their startup. This paper takes the form of a case study that first describes the founding story of one startup, TweetPhoto, with specific attention paid to the elements that prompted the growth of TweetPhoto, despite not being the first entrant in the mobile photo-sharing category. As a "live" case, readers are then encouraged to explore and compare the initial actions of the founders of two very new ITbased startups, Instacanvas and Instapparel, in light of those made by the founders of TweetPhoto. Questions for class discussions and student research in entrepreneurship-related courses are provided.
\end{abstract}

\section{Introduction}

One look at the business news today and you'll see familiar words appearing over and over again: social, mobile, and instant. With the meteoric rise of social networking and mobile interaction, a newer form of community building is providing aspiring entrepreneurs with a fertile environment for launching new ventures. Due to the rising interestand millions of users-generated by Facebook, Twitter, and Instagram, IT entrepreneurs have realized that, in a few keystrokes, they can overcome one of the most challenging hurdles to starting a new venture: finding the customers most in need of the new product or service.

After witnessing the explosion of interest and investment in these new ventures, my curiosity was piqued and I began asking questions including: What is it about the early behaviors of these ventures that makes them particularly effective at gaining new users and finding traction in the marketplace? What specific actions do I see recurring among these

1 "Hitch your wagon to a star." -Ralph Waldo Emerson, 1862 ventures that propel them forward? After first experiencing as a user and then investigating as a researcher, I've isolated a few key behaviors and actions that are worth further inquiry and exploration.

Before exploring these three new IT ventures, it may be worthwhile to consider the transformation of communication in the broader society that has taken place over the past forty years. This change has provided opportunities for new ventures like these to emerge [4]. While much has been written on the impact of each of the following technological changes on the transformation of communication, they can be broadly summarized in the following timeline: (i) creation of the Internet, (ii) creation and diffusion of personal computers, (iii) creation of World Wide Web and web browsers, (iv) global Internet penetration, ( $\mathrm{v}$ ) identification and concern regarding the "digital divide", and (vi) the addition of large numbers of Internet users in developing countries.

Alongside these computing technological advances, wireless communication exploded with increasing reliability in connectivity and bandwidth expansion leading to a convergence of the two. According to Castells, a Sociologist and leading communications scholar, the last decade prompted a

"new model of telecommunications; wireless communication has become the predominant form of communication everywhere, particularly in developing countries. The year 2002 was the first in which the number of wireless subscribers surpassed fixed-line subscribers worldwide. Thus, the ability to connect to the Internet from a wireless device becomes the critical factor for a new wave of Internet diffusion on the planet. [preface, 4]."

It is in the midst of these technological and social changes that the social media "stars" of Facebook, Twitter, and Instagram have emerged. For each, their near immediate success and growth would not have been possible without these changes.

In this paper, we will not spend much time on these three "star" ventures, but rather will look at 
three IT startups that have harnessed the large user base communities and near-instant communication forms to launch their own venture.

By exploring and evaluating these ventures, students will: (i) understand how the founders of a new venture establish linkages in the marketplace as a means to legitimize their venture; (ii) explore various actions that a new venture founder can use to generate awareness, increase effectiveness, and speed uptake of the service/product provided; (iii) be invited to explore the "live" experiences of two new ventures launched in 2012. This paper presents an exploration into the benefits of hitching a new IT venture-or "wagon"-to an existing "star" that is, at the time, experiencing exceptional growth and unprecedented exposure in the media. Additionally, students are encouraged to consider the importance of "pivoting" when the environment changes and the drawbacks of tight linkages become evident.

To better situate a student's own analysis and exploration of the two newest startups, I first present a condensed history of TweetPhoto, which came onto the scene in 2009.

\section{TweetPhoto, circa March 2009}

With near instant communication and the ability to harness the untethered aspects of wireless communication, Twitter users began to explore the expansive use of texting conventions (e.g., lol=laugh out loud; rotfl=rolling on the floor laughing; etc.) and Twitter-specific symbols including \# hashtags and @ referencing. News and new media sites glommed onto this unique vernacular and Twitter took off as a new form of news distribution and with it brought interest from angel investors and venture capitalists.

Twitter's exponential growth piqued interest by many entrepreneurially-minded individuals to take advantage of what could be construed a "shooting star" and, by mid-2008, there were more than 140 twitter-related apps and services [9]. An early report on the funding for Twitter-related venture creation indicated that more than $\$ 23$ million had been directed to eleven of these ventures [6].

While working on a master's thesis project, Sean Callahan developed an idea for an IT startup that integrated the sharing and posting elements of Twitter with the desire that many individuals expressed to capture their daily moments in a photo and share these alongside their 120-character "tweets".

Sean's thesis explored the collaboration potential of social networking sites like Twitter, which at that time was less than two years old. While conducting his research, Sean discovered that many of the people he was interviewing mentioned some desire to have an ability to share more than just words via the Twitter interface, but wanted to still benefit from Twitter's online community. Drawing from his own experiences on Twitter and by the specific interactions he had with other Twitter users, Sean recognized an opportunity to provide a new IT-based photo-sharing site that linked Twitter with mobilebased photos. Sean used Twitter to begin the initial steps in planting the seeds of his new venture. He tweeted his intentions and invited a few thousand people to join as beta testers and early adopters [11]. One of those that he interacted with, in only an online and virtual space up to that point, was Rodney Rumford. He would go on to become Sean's partner and cofounder of TweetPhoto.

At launch in early 2009, their fledgling enterprise entered the market against two earlier entrants into the photo-sharing space: Twitpic and Yfrog. In a little more than a year after launch, TweetPhoto made up the difference (Figure 1) [18].

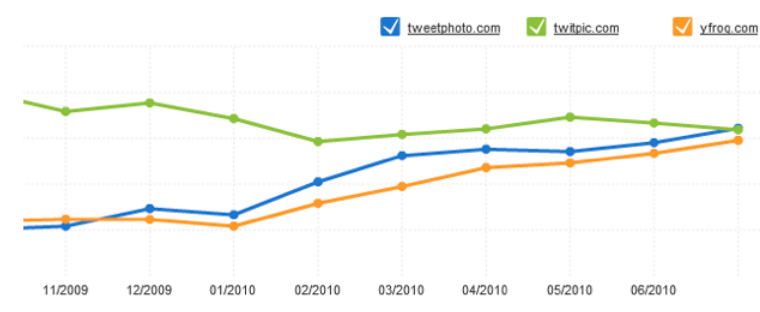

Figure 1. Twitter photo sharing usage statistics (from [4])

According to Alexa.com analytics, TweetPhoto gained considerable ground on Twitpic in the latter portion of 2009 and early 2010 (Figure 2) [15].

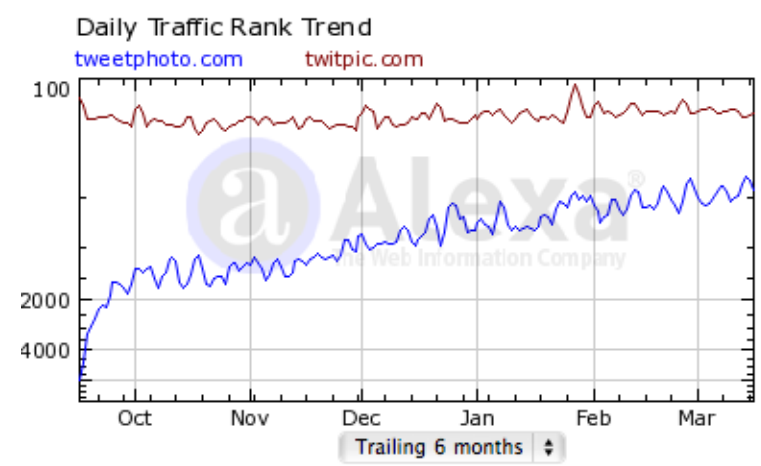

Figure 2. Daily Traffic Rank Trend for TweetPhoto and Twitpic, March 2010.

It is worthwhile to consider how TweetPhoto achieved this and what mechanisms the founders used to generate substantial growth, even in the midst of stiff competition from Twitpic, a "behemoth" first mover. 
Early and intentional linkage with the brand of the shooting star. TweetPhoto's first logo leaned heavily toward the branding elements familiar to Twitter users: puffy lettering and a simple blue and white color combination (Image 1).

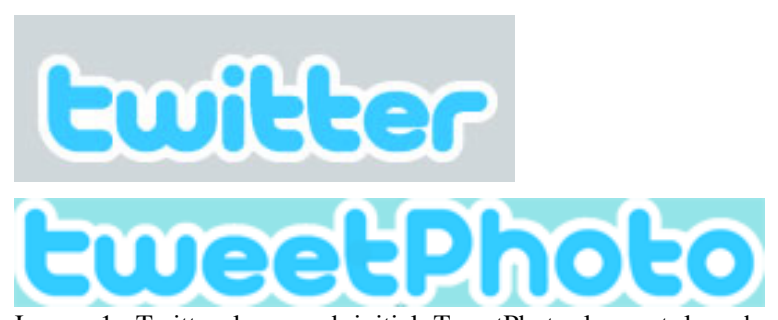

Image 1. Twitter logo and initial TweetPhoto logo at launch, March 2009.

During the beta invite phase (see below), the founders crowdsourced a $\$ 300$ design contest at crowdspring.com to generate further refined designs that added reference to the actual service being offered: photo sharing with that of a Twitter-like bird [15]. The details listed on the design contest site highlighted the founders' interest in linking up the brand familiarity of Twitter with their own brand: "The graphic needs to be fun and friendly and have a Twitter-like feel." Twitter's recognizable font type, rotund bird, and polaroid-like image added to the final design selected by the team (Image 2). Note that, to this point in the founding story in April 2009, TweetPhoto had not been formally launched. Beta invites were underway and interest was mounting.

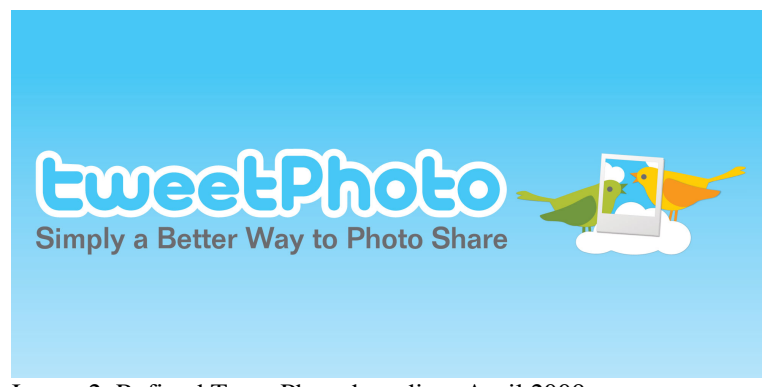

Image 2. Refined TweetPhoto branding, April 2009

Offering a limited number of invitations to beta launch the service. With a rudimentary logo design in place and a firm concept in mind, Sean focused his attention to the ageless activity of the fledgling venture: gaining the first customer.

In social space, individuals don't want to be left out. TweetPhoto harnessed this aspect of human behavior and utilized it to grow their user base. A screenshot of their website from April 16, 2009 identifies a variety of elements they used to enhance uptake by new users (Image 3): beta invites were only provided to the first 5000 users; exclusive badges-popular at the time on Twitter-indicate a "first to be invited to the party", enhancing the exclusivity of the new service: "I'm invited. Are you?" and "I was first. Were you?" [16]

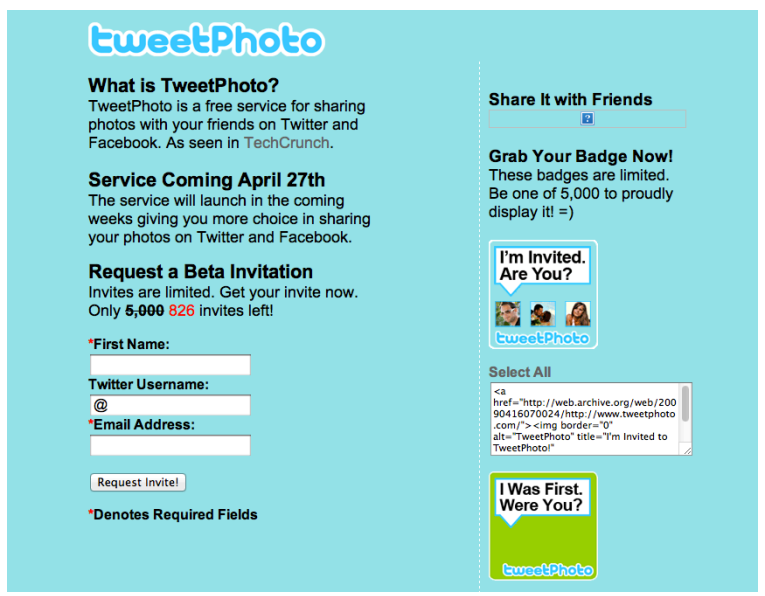

Image 3. TweetPhoto website, April 16, 2009.

Ensuring fast, reliable, and responsive service. One of the main benefits of mobile devices is the ability to communicate with anyone, anywhere, nearly instantaneously. Users of mobile devices have come to expect that their devices will respond to their needs; when the user presses "send" or "submit, the device responds accordingly, reliably and instantly. When that doesn't occur, mobile users are reluctant to stick with an unreliable service.

Early on in launching the service, Sean and Rodney closely monitored their blogs, twitter accounts, and techie websites for any mention of concerns from users. When problems arose, the founders quickly worked to resolve them. Sean's blog entry from May 9, 2009 speaks to this responsiveness [1]:

"It's been about one week now since the soft launch of TweetPhoto. There has been a lot of activity on the site in just 7 days time. Enough activity to find out where the bugs are, the likes and dislikes of users. People from all over the world have posted photos to the service through the web, email and their mobile device. Although the site has had some hiccups and there are still some bugs outstanding, we've received some good feedback from current users. @Rumford and I did a show last week on Ustream.tv to solicit feedback and to share our favorite photos. We plan on doing this at least once a week. We hope you can join us when we do. 
We're all about creating a better way to photo share and can't do it without the feedback of you! Each day we're implementing new bug fixes for mobile phones and email. Some providers of mobile devices send multiple attachments in each email, unknown file formats, binary photo attachments among other things.

As I stated a few weeks back, we're all about customer service. I can assure you we'll get these fixed in due time. We'll also get the service integrated into many of your favorite mobile apps for both the BlackBerry and iPhones. Our plan is within the next 30 days is to make TweetPhoto rock solid. As we work hard to make TweetPhoto the best Twitter Photo sharing service on the web we hope for your continued support of something really cool to come!

PS - Please help us spread the word by tweeting an invite to your friends today!"

Less than a month after launch, the TweetPhoto site was subjected to a virus attack rending the site with a "This site may harm your computer" warning on Google. Sean's blog entry from May 19, 2009 [2] documents the business' response to this challenge:

"UPDATED: TweetPhoto has been fully restored and stronger than before.

You may or may not know, but TweetPhoto was attacked 3 times in the last 24 hours. Every time the site has been attacked we've quickly responded by removing the virus. It's been a battle between us and the transforming Gumblar virus, which is now morphed to what is known as the Martuz virus.

I want to let you know that we're on top of this issue. Because this site has high traffic and many of our users use Google Chrome and Firefox, every time they access the site when the virus was present it notified Google of the potential malware. With that said, Google has since placed a notice on their site that says "This site may harm your computer" when you try to access TweetPhoto.

I can assure you that the threat has been removed, but the warning message has not. We've contacted Google to remove the warning message on the site and will keep you posted of any further developments. I have already uploaded many photos this morning without any issues. If you have any questions do not hesitate to contact us."
In a response to user concerns about speed and efficiency of the photo sharing service, the founders moved the service to a managed cloud-based server provider to accommodate the increased traffic and to be able to flex with the unpredictability that comes with an increasingly social, mobile, and instant user base. Sean attributes that decision as a key to growing the business and gaining the confidence of key users to trust the system with their photos [3].

Gaining buy-in from key users currently using the services offered by the "star". One of the things that Sean learned while conducting his thesis research was the importance of key users in strengthening the collaboration and alignment of the network users. Where a social network was strong, it wasn't only dependent on one key user, but having at least one key user was an important element for collaboration. This was one of the initial reasons that Rodney and Sean worked together; Sean recognized the socialnetwork capital that Rodney brought by being a very visible Twitter user and by directing the conversation regarding Twitter and social media in general.

As an interested observer of the initial planning, startup, and launch of TweetPhoto, I witnessed the service take a huge leap in users, photo views, and site visits soon after launch. While much of this could be attributed to general diffusion of the technology and the organic interest generated by users in their exploration of the service, I also noticed that many of the "Top Photos of the Day" on TweetPhoto were from screen and music celebrities. One such celebrity, Britney Spears, was launching her comeback concert tour in 2009. At the time, Britney Spears was one of the most followed celebrities on Twitter and every time she (or her publicist) posted a photo to her Twitter account and thereby referencing TweetPhoto, fans and followers were directed to her TweetPhoto feed. Sean remarked that in July 2009, Britney Spears was the "most commented and favorited photo" on the entire TweetPhoto site [13].

The homepage for TweetPhoto on July 18, 2009 demonstrates the importance of celebrity-centric photos in driving users to the site and increasing user behavior in "consuming" the photos (Image 4). Note that Britney Spears-related photos occupy 5 of the 16 highlighted spots on the homepage. Not only did this encourage new users to sign up for the service so they could "favorite" her photos, but they were also exposed to a viable photo-sharing service that the celebrities were unofficially endorsing because of their use. This led to further expansion of the brand and broader reach for the new venture. 


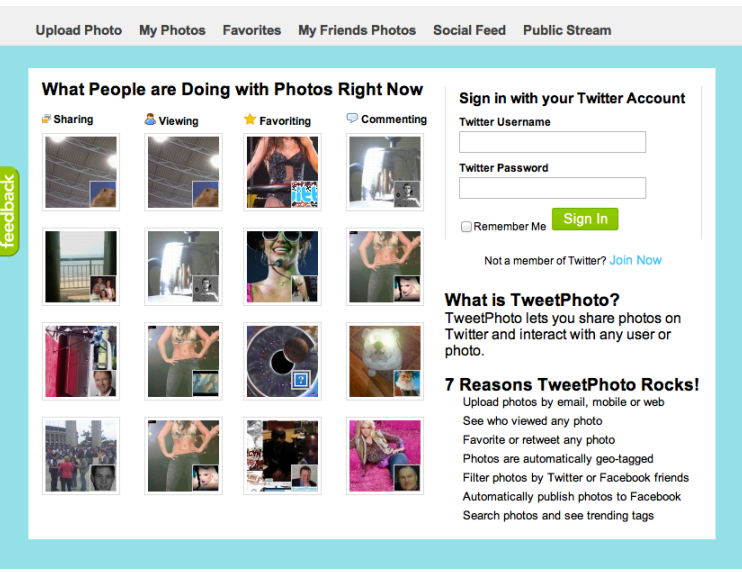

Image 4. TweetPhoto homepage, July 18, 2009.

Opening the IT-related venture and sharing the "guts" of the data with other new venture developers to spur growth and further integration in the marketspace. TweetPhoto witnessed the explosive growth and importance of API distribution and wanted to capitalize on the power of multiplicative innovation by releasing their API.

The growth of APIs in the broader development community continues to accelerate, with social and mobile claiming the lions share of the growth in 2010 and onward [7]. According to ProgrammableWeb's API Directory, there's been a more than 25 -fold increase in the distribution of open APIs from 2005 to 2010 (Image 5).

\section{Open API timeline}

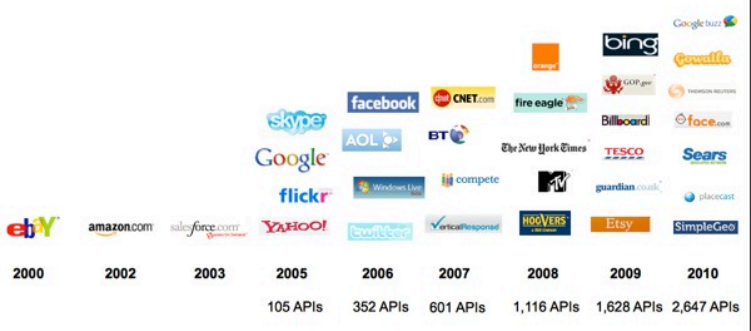

Image 5. ProgrammableWeb's API Directory Growth from 2000 to 2010.

Following eBay's initial release of its API in 2000, more than 5000 APIs have been released to the developer community in the $21^{\text {st }}$ century. Twitter leads the way with more than 100 APIs released to date. The most popularly used API is Google Maps mapping service, with Twitter a distant but important second. YouTube, Flickr, Amazon eCommerce, and Facebook round out the top six [8].
Early on in their venture launch, Sean and Rodney decided to provide an open API (application programming interface) to encourage innovation and further development of TweetPhoto-based services and applications.

In their June 2009 press release packet for the first release of the API, Sean stated, "We are very excited to open up our entire photo sharing platform to the Twitter developer community [14]." TweetPhoto further established a kinship with developers by pairing the release of the API with an offer to direct $100 \%$ of Google AdSense revenue to developers for ensuring TweetPhoto as the default photo sharing service within the developer's application.

Creating strategic partnerships that further establish the credibility of the new venture. In November 2009, TweetPhoto announced the securing of a strategic partnership with Kodak, a historical leader in photography and imaging. Kodak had been straining for relevance in the new world of digital, film-less photography. Rodney's blog post from November 21, 2009 describes the synergies expected to yield from this relationship:

"We are announcing that we have struck a partnership agreement with Kodak, under which the two companies intend to collaborate on initiatives focused around real-time photography and photo sharing on the web. Basically, that means that we will be co-developing, testing and launching new products and services together, centered around the nature of the real-time web, social networks and image sharing.

We were on a photo sharing panel and in the Kodak booth at the LA 140 Conference 2 weeks ago demoing a real time event photostream on a 40 inch monitor.

The event stream product displayed photos that were shared real-time at the event as well as associated tweets from the event in real-time... and as Kodak CMO Jeffrey Hayzlett said at the conference "It's not a Kodak moment until you share it". Stay tuned for further details as we move forward in this mutually beneficial relationship with industry leader Kodak. To say we are thrilled would be an understatement."

Soon thereafter, TweetPhoto and Kodak announced a co-branded contest for Kodak product and TweetPhoto exposure. The "30 Days. 30 Giveaways." promotional campaign sought to bring awareness to Kodak's new social networking-rich products and further establish TweetPhoto as the de facto social networked photo sharing service. The 
contest environment provided a deadline for user involvement, the possibility of winning a desirable prize, and the gathering of many additional users to the site.

Responding to a substantial change in behavior by the star and "pivoting" to a new strategic direction. As Twitter continued to grow and expand throughout 2009, Twitter began to exhibit behaviors consistent with a more established brand and sought to protect their brand by locking down the references to Tweet and Twitter by other ventures. Understandably, this caught TweetPhoto by surprise and it became clear that either TweetPhoto would go away - due to the potential of lawsuit from Twitteror TweetPhoto would emerge as a different sort of business with a different moniker.

Sean refers to this moment in their founding story as their opportunity to pivot. Twitter's strong "encouragement" to change any and all references to Twitter or Tweet in the branding and naming of their company provided TweetPhoto with the opportunity to rethink their brand and their less-than-one-year-old business. While they likely could have fought this mandated change by Twitter and spent money defending their own brand name, TweetPhoto instead took the opportunity to evaluate what it was that they were offering their users and decided to more broadly define their company as a mobile photo sharing and social networking site.

During this refocusing and pivoting away from a Twitter-centric name, the founders settled on the name of Plixi. Their playful, puffy-lettered logo and familiar coloring hinted at their roots as a Twitterinfused service, but didn't tie them so directly to the star (Image 6).

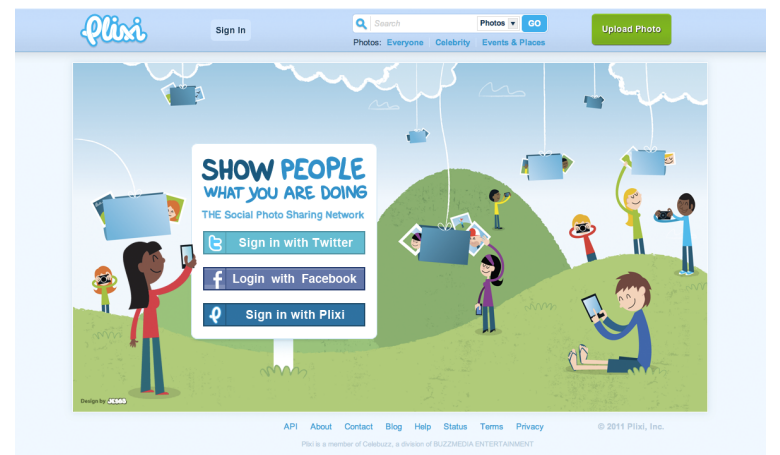

Image 6. Plixi homepage following name change and "pivot".

It was during this time that TweetPhoto/Plixi began to unhitch their wagon from the Twitter star, albeit not completely. With this change away from Twitter-only labeling, Plixi emerged as a social media sharing platform that no longer depended on and, in fact, seemed to eschew the earlier ties to Twitter. Rodney's entire blog post, but especially the last line, from January 19, 2010 [12] conveys this sentiment:

"We have been going thru [sic] some major enhancements and changes to our service since we launched in April of last year. Consequently we wanted to redo our logo to more accurately reflect our vision and what we have become as a company. Tweetphoto is a photo sharing platform for the real time web.

This means that we are going beyond just sharing photos on Twitter. We are facilitating sharing of photos across multiple social ecosystems. Additionally we have an ever growing presence in the mobile space.

So tell all your designer friends that we have created a contest (the winner gets a cash prize) to select a new logo for Tweetphoto. We will be selecting a winner in the next 7 days. The full details and entries for the tweetphoto logo redesign contest can be found here: http://99designs.com/contests/35518

Tip: Birds in the design = bad. Mobile $\&$ photo sharing = good."

Now that we've examined some of the early decisions that led to TweetPhoto's strong growth throughout 2009 and 2010, let's turn our attention to two new "wagons" that are hitching up with the newest social media darling, Instagram. Purchased by Facebook in early 2012 for $\$ 1$ billion, Instagram has brought the attention of many IT-minded entrepreneurs. What follows is a brief description of two of these ventures that have only recently made their foray into the market. This is intended to provide a launch point for further discussion and exploration of Instacanvas and Instapparel as their fledgling businesses set root in the market space of social, mobile, and instant photo sharing.

\section{Instacanvas, official launch May 2012}

Millions of photos are posted and shared on Instagram each day. While many users are satisfied to have those photos remain as digital renderings in an online space, other users desire to post their favorite photos in a physical space (e.g., on a wall in an office or living room). Instacanvas was born from this desire to permanently display a mobile-generated photo. The founders of Instacanvas paired up the existing services of photo enlargement and custom canvas printing with the immediacy and social networking aspects of Instagram. For less than $\$ 100$, 
a user can select one of their own photos or one from a gallery of a featured artist, get it printed on a highquality canvas, and shipped to their residence all with just a few simple clicks on the site.

The initial release of the service saw intentionally limited functionality and restricted creation of user galleries. Although many Instagram users requested the creation of their own gallery, not every Instagram user could have their own Instacanvas gallery created. This created a sense of pent up demand and exclusivity. In so doing, Instacanvas fueled growth of their own site by requiring that new galleries only were opened as a result of "Requests for Gallery Openings". These requests had to come from a sufficient enough number of Instagram users for a specific Instagram user's gallery.

The process for opening a gallery is as follows: (i) Instagram user (or "artist" in Instacanvas terms) requests an Instacanvas gallery be created so that users may purchase photographs from the artist's gallery of Instagram photos; (ii) Instacanvas responds by indicating that only a certain number of galleries can be created each week and that the best way to speed up gallery creation is to get the artist's network of followers to request the creation of the gallery via Instacanvas; (iii) Instacanvas provides the artist with a variety of Instagram-friendly, Facebook-friendly, and Twitter-friendly images to encourage followers to respond by requesting the opening of the artist's gallery; (iv) at some unknown time in the future, the Instacanvas gallery is created and sales of the artist's photos can commence.

Instacanvas' homepage conveys the key features of their service offering: the highlighting of featured artists, an easy mechanism to purchase canvases, and a process for new users to create their own gallery (Image 7). Access to all features of the site are unlocked by logging in with the user's Instagram credentials.

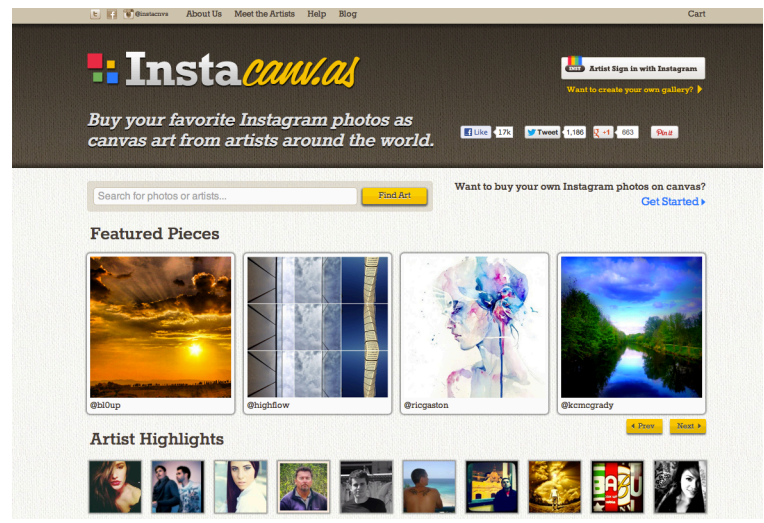

Image 7. Instacanvas homepage (note instacanv.as domain)
This new IT-based venture is experiencing "rocketship, viral growth without spending a dime on advertising," according to CEO Matt Munson. [Note that he said this the week of the official launch in May 2012 and not some weeks after.] According to the same report, Instacanvas ran an eight week "private beta" and, at time of launch, was hosting more than 25,000 user galleries [17]. How many new ventures can claim that they have 25,000 customers before they ever open their doors to the public? Not many. Therein lies the power of social, mobile, and instant communities to fuel new IT ventures.

\section{Instapparel, official launch June 2012}

As of the writing of this paper, Instapparel has not officially launched. Avid users of Instagram have likely come across mention of Instapparel and may even follow@instapparel's photo feed. Due to its newness, little is known about who it is that is behind Instapparel and their motivations and ambitions. This is what makes the case live and particularly intriguing to examine.

The buildup to Instapparel's launch has been in the works since April 2012 with the first mention on Instagram coming from a rather innocuous "\#instapparel" hashtag on a photo of a classic Cadillac, posted by one of the founders on Instagram.

From what can be gathered on their Twitter and Instagram feeds (both @instapparel) and their website (instapparel.com), the venture is based in Costa Mesa, California and offers users a simple, high-quality cotton tee printed with the user's choice of photos from their own, and presumably, other Instagram feeds (Images 8 \& 9).

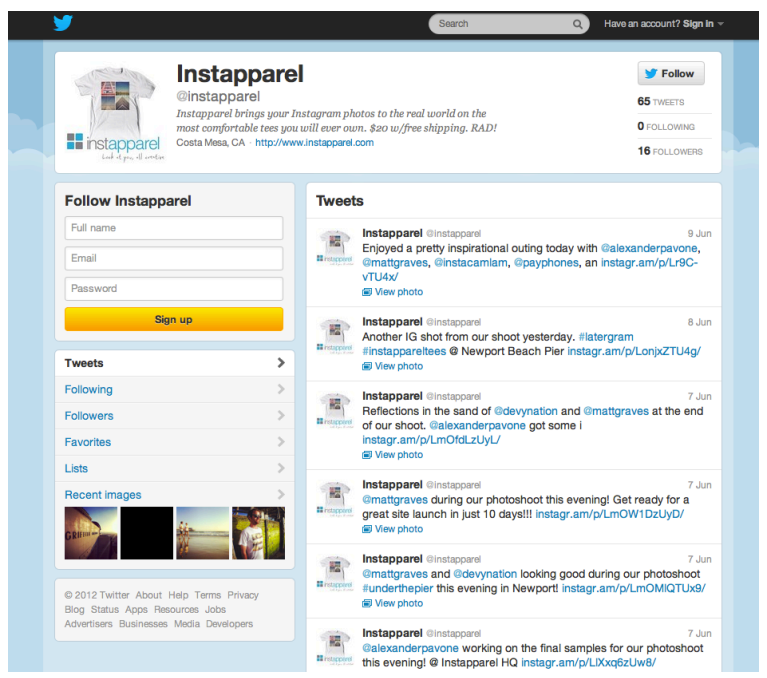

Image 8. Instapparel's Twitter feed on June 12, 2012 


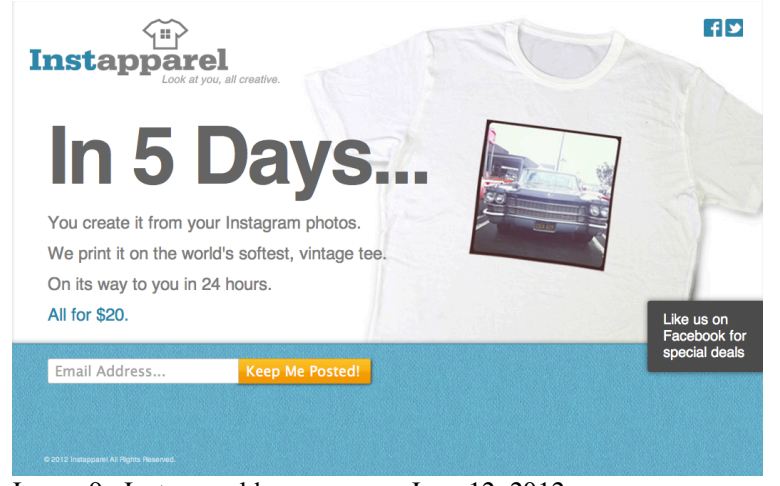

Image 9. Instapparel homepage on June 12, 2012

What will Instacanvas and Instapparel experience in the upcoming months? How will Instacanvas and Instapparel fare in 2013 and beyond? That's the value of this type of live case study; it is unfolding before us to examine and investigate.

\section{Questions for Reflection and Discussion}

This case study is useful to enhance class discussions regarding the initial decisions made in launching a new IT-based entrepreneurial venture. Included below are a few discussion starters that draw on material included in the case and encourage students to do further research on the two newest ventures, Instacanvas and Instapparel.

1. What are the pros and cons of "hitching your wagon to a star"? Specifically, what lessons can be learned from TweetPhoto's experience with Twitter and Instacanvas' experience with Instagram? Suppose for a moment that following Facebook's acquisition of Instagram, Facebook decides to bring Instagram within the bounds of Facebook and changes the name of the service to "Facebookgram" or something similar...what would you do if you were the owner of Instacanvas or Instapparel? Is there a pivot that you could make to still stay relevant in each of these spaces: art gallery canvases and hyperindividualized clothing? If so, what is it?

2. Can you envision the world without Facebook, Twitter, or Instagram? All three of these are, or have been, shooting stars of the social, mobile, and instant communities in the past year. Will they persist as stars? If not, what warning signs would you look for to identify that a "shooting star" is becoming a "falling star"? What are some likely consequences of remaining hitched to a falling star?

3. Are you a user of Instagram? If so, why? If not, why not? More specifically, try to identify at least five elements that make the Instagram experience compelling. In your answer, be mindful of the opening statement regarding the newest form of telecommunications, mobile communications. Additionally, which of these compelling elements are present within the unique value propositions of Instacanvas and Instapparel?

4. As is probably apparent by now, TweetPhoto offered no tangible goods in their IT-based service delivery. Instacanvas and Instapparel both rely heavily on IT-based services, but also must deliver a quality, tangible product in the form of a piece of wall art or an article of clothing. In what ways does this make the IT-based entrepreneurship even more difficult for these two fledgling businesses?

5. The founders of TweetPhoto acknowledged the strategic benefits of partnering with Kodak who some would say is an old star of the photographic world. Although they saw this as a positive union, could you argue just the opposite? Is there any downside to linking up with the "old", when the "new" is all the rage? Relatedly, what potential strategic linkages could Instacanvas and Instapparel make in their young age with more established brands? What brands would you recommend that they pursue, and why?

\section{Conclusion}

This paper provides a case study of TweetPhoto, an IT-based entrepreneurial venture, and offers a vantage point of comparison to two new IT-based ventures launched in early 2012. This paper also describes the elements of the founding story that reflect the relationship between a fledgling IT-startup (referred to as a "wagon") and the larger IT-based venture (referred to as a "star") that the wagon has latched onto to propel itself forward in the competitive landscape.

Interestingly, the story of TweetPhoto/Plixi ends well. In January 2011, Plixi was purchased by Lockerz, a social commerce site primarily targeted at users between the ages of 13 and 30. Specific terms of the deal were not made public, but reports indicated the deal was worth somewhere in the range of $\$ 5$ to $\$ 15$ million [10].

\section{References}

[1] Callahan, S. (2009, May 9). @TweetPhoto is listening: Fixing bugs and implementing new features. TweetPhoto Blog. Retrieved from Way Back Machine http://web.archive.org/web/20090529 145135/http://www.tweetphotoblog.com/ 
[2] Callahan, S. (2009, May 19). TweetPhoto under attack: Site restored back to health. TweetPhoto Blog. Retrieved from Way Back Machine http://web. archive.org/web/20090529145135/http://www.tweetp hotoblog.com/

[3] Callahan, S. (2012, May 16). Personal interview.

[4] Castells, M., The Rise of the Network Society: The Information Age: Economy, Society, and Culture, Volume 1 ( $2^{\text {nd }}$ ed.), John Wiley \& Sons, UK, 2010 .

[5] Cherry, B. (2010, March). Can you interpret a line chart? Edge of Entrepreneurship Blog. Retrieved from http://www.edgeofentrepreneurship.com/2010/ 03/can-you-interpret-line-chart.html

[6] Chubby Research Team (2009, June 16). \$23.3 million has flown to twitter-based startups - Is this just the beginning? ChubbyBrain.com. Retrieved from http://www.chubbybrain .com/blog/233-millionhas-flown-to-twitter-based-startups---is-this-just-thebeginning/

[7] DuVander, A. (2011, January 3). API growth doubles in 2010, social and mobile are trends. ProgrammableWeb. Retrieved from http://blog. programmableweb.com/2011/01/03/api-growthdoubles-in-2010-social-and-mobile-are-trends/

[8] DuVander, A. (2012, February 6). 5000 APIs: Facebook, google, and twitter are changing the web. ProgrammableWeb. Retrieved from http://blog. programmableweb.com/2012/02/06/5000-apisfacebook-google-and-twitter-are-changing-the-web/

[9] Ningthoujam, P. (2008, May 24). Twittermania: $140+$ more twitter tools! Mashable. Retrieved from http://mashable.com/2008/05/24/14-more-twittertools/

[10] Rao, L. (2011, January 27). Exclusive: Lockerz acquires social photo sharing app plixi (formerly tweetphoto). TechCrunch. Retrieved from http://techcrunch.com/2011/01/27/exclusive-lockerzacquires-social-photo-sharing-app-plixi-formerlytweetphoto/

[11] Richmond, R. (2009, September 28). A Startup's tale, tweet by tweet. Wall Street Journal. Retrieved from http://online.wsj.com/article/SB1000 1424052970203550604574359362541707146.html\#a rticleTabs\%3Darticle
[12] Rumford, R. (2010, January 25). TweetPhoto Logo Redesign Contest. Retrieved from http://web.archive.org/web/20100125032325/http://bl og.tweetphoto.com/2010/01/19/tweetphoto-logoredesign-contest/

[13] Swartz, A. A. (2009, July 8). Twitter talk radio [Radio broadcast]. San Diego, CA: Square Martini Media. Retrieved from http://www.wsradio.com/ player/player.aspx ?player $=$ windows $\&$ segdate $=07080$ $9 \&$ segment $=3 \&$ show $=$ twittertalkradio

[14] TweetPhoto. (2009, June 23). TweetPhoto opens platform, twitter developer community profits. [Press release]. Retrieved from http://www.prweb.com/ releases/2009/06/prweb2559594.htm

[15] TweetPhoto Design Contest (2009, March 31). Crowdspring. Retrieved from http://www.crowd spring.com/project/847311_need-killer-logo-for-freephoto-sharing-service-for-twitter/

[16] TweetPhoto Website (2009, April 16). Retrieved from Way Back Machine http://web.archive.org/web/ 20090416070024/http://www.TweetPhoto.com//

[17] Van Grove, J. (2012, May 9). Instacanvas unveils online art gallery for instagram photogs. VentureBeat. Retrieved from http://venturebeat.com/ 2012/05/09/instacanvas/

[18] Wauters, R. (2010, August 10). The Twitter photo sharing horse race. TechCrunch. Retrieved from http://techcrunch.com/2010/08/18/the-twitterphoto-sharing-horse-race/ 